\title{
Rhodium-Catalyzed $[2+2+2]$ Cycloadditions of Diynes with Morita-Baylis-Hillman Adducts: A Stereoselective Entry to Densely Functionalized Cyclohexadiene Scaffolds
}

\author{
Martí Fernández, ${ }^{a}$ Magda Parera, ${ }^{a}$ Teodor Parella, ${ }^{b}$ Agustí Lledó, Jean Le Bras, \\ Jacques Muzart, ${ }^{\mathrm{c}}$ Anna Pla-Quintana, ${ }^{\mathrm{a}, *}$ and Anna Roglans ${ }^{\mathrm{a}, *}$ \\ a Institut de Química Computacional i Catàlisi (IQCC) and Departament de Química, Universitat de Girona, Campus de \\ Montilivi, s/n, 17071 Girona, Catalonia, Spain \\ Fax: (+34)-972-41-8150; phone: (+34)-972-41-8275; e-mail: anna.plaq@udg.edu or anna.roglans@udg.edu \\ b Servei de Ressonància Magnètica Nuclear, Universitat Autònoma de Barcelona, 08193 Cerdanyola, Catalonia, Spain \\ c Institut de Chimie Moléculaire de Reims, UMR 7312 CNRS - Université de Reims Champagne-Ardenne, B.P. 1039, \\ 51687 Reims Cedex 2, France
}

Received: January 11, 2016; Revised: February 23, 2016; Published online: $\mathbf{D}$ II, 0000

Supporting information for this article is available on the WWW under http://dx.doi.org/10.1002/adsc.201600039.

\begin{abstract}
A rhodium-catalyzed asymmetric synthesis of 5,5-disubstituted cyclohexa-1,3-dienes has been achieved by $[2+2+2]$ cycloaddition reactions between diynes and Morita-Baylis-Hillman (M-B$\mathrm{H})$ adducts as unsaturated substrates. Products containing two adjacent chiral centres (quaternary and tertiary, respectively) were obtained with complete diastereoselectivity and high enantioselectivity (8497\%) through a kinetic resolution of the M-B-H adduct. Furthermore, these highly substituted cyclohexadienes reacted with dienophiles to afford the corresponding Diels-Alder cycloadducts in good yields.
\end{abstract}

Keywords: cycloaddition; diastereoselectivity; kinetic resolution; Morita-Baylis-Hillman adducts; rhodium

Opposite enantiomers of chiral compounds often display disparate bioactivity profiles. In particular, the introduction of quaternary stereocentres in a molecule constitutes an efficient strategy to complement the chiral three-dimensional space of biological receptors. This approach has long been recognized by medicinal chemists but is not straightforward from a synthetic point of view. In fact, all current marketed drugs of this type derive from natural products already containing the required quaternary stereocentres. Indeed, the formation of all-carbon quaternary stereocentres represents one of the most difficult contemporary challenges in synthetic organic chemistry since the creation of such centres is hampered by steric repul- sion between the carbon substituents. ${ }^{[1]}$ The transition metal-catalyzed $[2+2+2]$ cycloaddition reaction of unsaturated motifs is a well-established and atom-economical protocol for the construction of six-membered ring systems ${ }^{[2]}$ and various substrates have been used in this reaction, including alkenes. ${ }^{[3]}$ In the presence of a chiral ligand, the Rh-catalyzed $[2+2+2]$ cycloaddition between diynes and 1,1-disubstituted alkenes provides an approach to the enantioselective synthesis of cyclohexadiene derivatives (Scheme 1). ${ }^{[4]}$

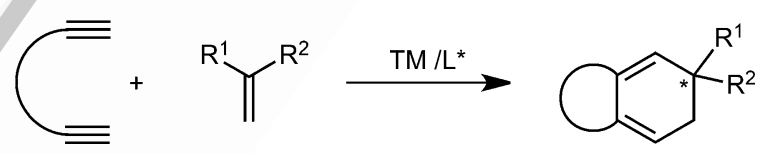

Scheme 1. Transition metal-catalyzed $[2+2+2]$ cycloaddition reactions of diynes with 1,1-disubstituted olefins.

Morita-Baylis-Hillman (M-B-H) adducts are readily available, densely functionalized molecules containing at least three functional groups in proximity, which can participate in a wide range of organic transformations. ${ }^{[5]}$ To the best of our knowledge, the participation of M-B-H adducts as alkene substrates in transition metal-catalyzed $[2+2+2]$ cycloaddition reactions has not been reported previously. With this transformation in mind, we hypothesized that the presence of an alcohol in the vicinity of the double bond would enhance stereodiscrimination through substrate chelation or anchimeric assistance. ${ }^{[6]}$ In this scenario, a highly diastereoselective process can be envisaged. In the event of using a chiral catalyst, a kinetic resolution process can be foreseen as well. ${ }^{[6]]}$ For this reason, we decided to study the $[2+2+2]$ cy- 
Table 1. Optimization of the $[2+2+2]$ cycloaddition between $\mathbf{1 a}$ and $\mathbf{2 a}{ }^{[a]}$

\begin{tabular}{|c|c|c|c|}
\hline Entry & Ligand & $T\left[{ }^{\circ} \mathrm{C}\right] /$ time & Yield $[\%]^{[\mathrm{b}]} / e e^{[\mathrm{c}]}$ of $\mathbf{3 a}[\%]$ \\
\hline $1^{[\mathrm{d}]}$ & (rac)-BINAP & $84 / 22 \mathrm{~h}$ & $0 /-$ \\
\hline 2 & $(r a c)$-BINAP & $80(\mathrm{MW}) / 10 \mathrm{~min}$ & $27 /-$ \\
\hline 3 & $(R)$-BINAP & $60(\mathrm{MW}) / 20 \mathrm{~min}$ & $50 / 93$ \\
\hline 4 & (R)-BINAP & $40(\mathrm{MW}) / 40 \mathrm{~min}$ & $0 /-$ \\
\hline $5^{[\mathrm{e}]}$ & $(R)$-BINAP & $84 / 4.5 \mathrm{~h}$ & $55 / 73$ \\
\hline 6 & $(R)-\mathrm{H}_{8}-\mathrm{BINAP}$ & $60(\mathrm{MW}) / 20 \mathrm{~min}$ & $47 / 95$ \\
\hline 7 & $(R)$-SEGPHOS & $60(\mathrm{MW}) / 20 \mathrm{~min}$ & $35 / 72$ \\
\hline 8 & (R)-DTBM-SEGPHOS & $80(\mathrm{MW}) / 40 \mathrm{~min}$ & $0 /-$ \\
\hline $9^{[\mathrm{f}]}$ & $(S)$-BINAP & $60(\mathrm{MW}) / 20 \mathrm{~min}$ & $24 / 81$ \\
\hline $10^{[\mathrm{g}]}$ & $(R)$-BINAP & $60(\mathrm{MW}) / 10 \mathrm{~min}$ & $51 / 94$ \\
\hline
\end{tabular}

[a] Conditions: 1a (1 equiv.), 2a (1.5 equiv.).

[b] Yield of the isolated product based on $\mathbf{1 a}$.

[c] Enantiomeric excess determined by chiral HPLC.

[d] Homocoupling product 4a and isomerized M-B-H adduct 5 were obtained.

[e] Slow addition of the diyne to a mixture of catalyst and $\mathbf{2 a}$ with a syringe pump for $4 \mathrm{~h}$.

[f] The enantiomer obtained in this case was the opposite to that obtained using $(R)$-BINAP.

[g] Reaction run in ethanol.

cloaddition of symmetrical diynes with M-B-H adducts in order to obtain bicyclic cyclohexa-1,3-dienes with a tertiary/quaternary stereodiad (Table 1 ).

The feasibility of the cycloaddition was assessed with $N$-tosyl-tethered non-terminal diyne 1a and M$\mathrm{B}-\mathrm{H}$ adduct 2a using $10 \mathrm{~mol} \%$ of cationic rhodium complex $\left[\mathrm{Rh}(\mathrm{COD})_{2}\right] \mathrm{BF}_{4}$ with ( $\mathrm{rac}$ )-BINAP in refluxing dichloroethane (DCE) (Table 1). Only undesired homocoupling product $\mathbf{4 a}$ and isomerized M-B-H adduct 5 (Figure 1 ) were obtained (entry 1, Table 1). The effect of microwave as the heating source was then evaluated by running the reaction at $80^{\circ} \mathrm{C}$ for $10 \mathrm{~min}$. A $27 \%$ yield of $\mathbf{3 a}$ was obtained and the formation of both $\mathbf{4 a}$ and $\mathbf{5}$ was reduced. Careful ${ }^{1} \mathrm{H}$ NMR analysis of $\mathbf{3 a}$ showed the formation of only one of the two possible diastereoisomers, demonstrating the high diastereoselectivity of the process. However, due to free rotation about the $\mathrm{C}-\mathrm{C}$ bond linking

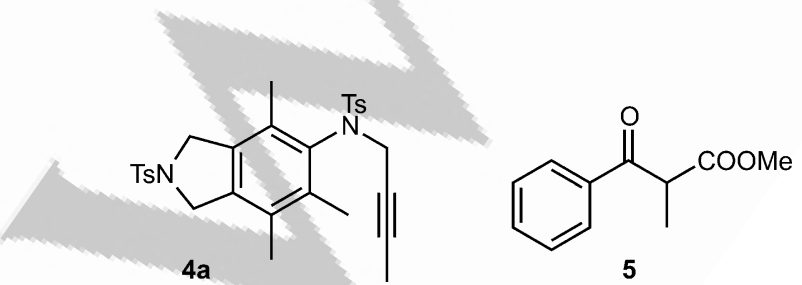

Figure 1. Homocoupling product $\mathbf{4 a}$ and isomerization product 5 . the two stereocentres, it was not possible to determine their relative configuration by NMR spectroscopy.

We then studied the stereoselectivity of this cycloaddition using various chiral phosphines. To our delight, the use of $(R)$-BINAP at $60^{\circ} \mathrm{C}$ led to a better yield of 3a with excellent enantioselectivity (entry 3 , Table 1). A single X-ray crystallographic analysis of $3 \mathbf{a}^{[7]}$ revealed an $(R)$-configuration for the quaternary stereogenic centre and an $(S)$-configuration for the tertiary alcohol stereogenic centre (Figure 2). Having started from racemic M-B-H adduct $\mathbf{2 a}$, an enantioenriched cycloadduct was obtained, suggesting that a kinetic resolution process was operative. The recovered unreacted M-B-H adduct was submitted to chiral

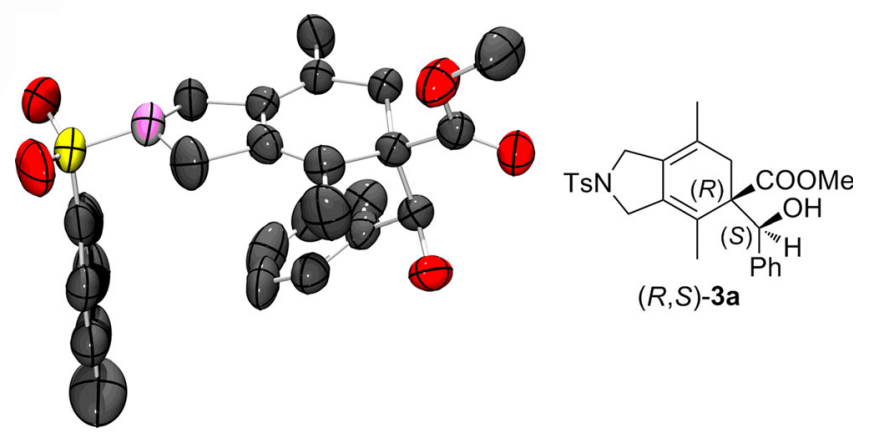

Figure 2. ORTEP diagram of cycloadduct $(R, S)-\mathbf{3 a} \cdot{ }^{[7]}$ 
HPLC analysis resulting in an ee of $17 \%$, which corroborated our hypothesis. ${ }^{[8]}$

An attempt to reduce the temperature to $40^{\circ} \mathrm{C}$ resulted in a complete loss of reactivity (entry 4, Table 1). We then evaluated the ee obtained under conventional heating using slow addition of the diyne 1a to avoid its homodimerization (entry 5, Table 1). The yield of 3a was similar but the enantioselectivity was lower $(73 \%$ instead of 93 , entries 5 and 3 , Table 1). Different axially chiral biphosphines were then tested in dichloroethane under microwave heating. Whereas $(R)-\mathrm{H}_{8}$-BINAP provided analogous yields and ees (entry 6, Table 1 ), the use of both $(R)$ SEGPHOS and especially $(R)$-DTBM-SEGPHOS gave worse results (entries 7 and 8 , Table 1 ). As a result, $(R)$ - and $(S)$-BINAP were chosen for the rest of the study. (S)-BINAP promoted the reaction of the other enantiomer of the M-B-H adduct to afford $(S, R)$-3a with $81 \%$ enantiomeric excess; however, the yield was lower than when $(R)$-BINAP was used (compare entries 3 and 9, Table 1).

In all the above experiments, isomerization of $2 \mathbf{a}$ to ketone 5 occurred consistently. A cationic rhodium system with $(R)$-BINAP has recently been described ${ }^{[9]}$ in which a non-coordinating solvent such as dichloromethane (DCM) favours the isomerization of allylic alcohols to saturated carbonyl compounds and so we decided to evaluate the effect of the solvent. Using EtOH, 3a was obtained in a $51 \%$ yield and with $94 \%$ of $e e$ and, importantly, no trace of the isomerized compound was detected (entry 10, Table 1). Two control experiments were carried out to determine whether or not the isomerization process was rhodium-catalyzed. Treatment of M-B-H adduct 2a with the Rh-catalytic system in DCE at $80^{\circ} \mathrm{C}$ for three hours led to its quantitative conversion into 5 . We then repeated the experiment in EtOH. The M-B-H adduct was submitted to $\mathrm{MW}$ heating in EtOH $\left(10 \mathrm{~min}\right.$ at $\left.60^{\circ} \mathrm{C}\right)$. Starting material alone was recovered, indicating that $\mathrm{EtOH}$ prevents isomerization. Additionally, in the reaction of entry 10 (Table 1), the recovered $\mathrm{M}-\mathrm{B}-\mathrm{H}$ adduct was obtained in $43 \% e e$, confirming that the lower ee previously observed originates from the isomerization process.

The kinetic resolution process was then analyzed in greater detail. First, a $[2+2+2]$ cycloaddition reaction was set up using an excess of diyne 1a [Eq. (1), Scheme 2]. We obtained $(R, S)-\mathbf{3 a}$ in a $50 \%$ yield and $86 \% e e$, together with an excess of diyne homocoupled compounds and $(R)-\mathbf{2 a}$ in a $48 \%$ yield and an excellent $98 \%$ ee The $S$-factor for the kinetic resolution of $\mathbf{2 a}$ was determined to be 64 . Therefore, the rhodium-catalyzed $[2+2+2]$ cycloaddition reaction developed appears to be a potentially efficient way to resolve M-B-H adducts.

Further insight into the resolution process was gained by treating the enantioenriched M-B-H adduct

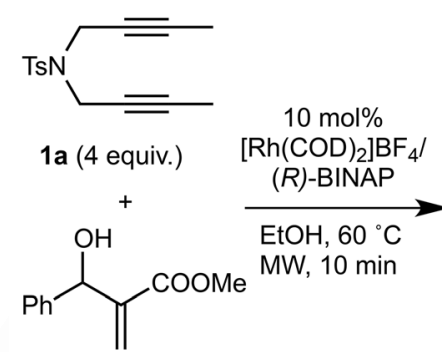

$2 \mathbf{a}$ (1 equiv.)

(conversion of $\mathrm{B}-\mathrm{H}: 53 \%)^{[\mathrm{a}]}$

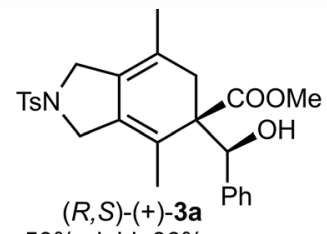

$50 \%$ yield, $86 \%$ ee

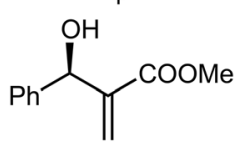

(1)

$(R)-2 a$

$48 \%$ yield, $98 \%$ ee

S-factor ${ }^{[b]}=64$
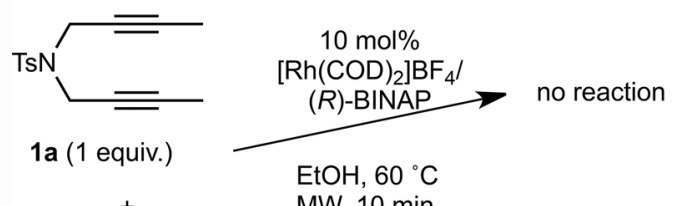

$\overbrace{1}^{c+}$

(R)-2a (1.5 equiv.)

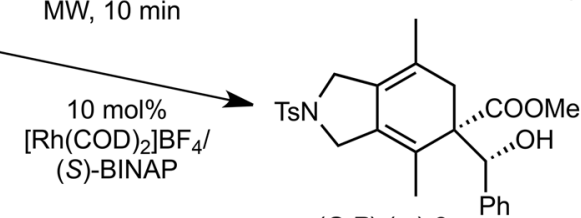

$(S, R)-(-)-3 a$

$53 \%$ yield, $98 \%$ ee

[a] Conversion of $(r a c)-2 a=e e_{2 a} /\left(e e_{2 a}+e e_{3 a}\right)$.

[b] $S$-factor $=\ln \left[(1-\right.$ conv. $\left.)\left(1-e e_{2 a}\right)\right] / \ln \left[(1-\right.$ conv. $\left.)\left(1+e e_{2 a}\right)\right]$.

Scheme 2. Kinetic resolution of M-B-H adduct 2a [Eq. (1)] and cycloaddition reactions with enantioenriched $(R)-\mathbf{2 a}$ [Eq. (2)].

$(R)$-2a with 1a under the optimized reaction conditions (entry 10, Table 1) with either $(R)$ - or $(S)$ BINAP [Eq. (2), Scheme 2]. As expected, no cycloadduct was isolated in the reaction with $(R)$-BINAP. On the other hand, $(S)$-BINAP efficiently promoted the cycloaddition of $(R)-\mathbf{2 a}$ to $(S, R)$-3a, corroborating the high enantiospecificity of the process.

Finally, the cycloaddition of $\mathbf{1 a}$ with $\mathbf{2 a}$ was monitored over time in a reaction carried out under conventional heating, which has a longer reaction time than that run under microwave heating. This kinetic experiment revealed a rapid consumption of $(S)-2 \mathbf{a}$ to form $(R, S)$-3a cycloadduct with a high enantiomeric excess, which did not decrease over time. After approximately $2.5 \mathrm{~h}$ of reaction, the cycloadduct yield and the ee of the M-B-H adduct reached a plateau indicating that $(R)-\mathbf{2 a}$ does not react at a significant rate under the reaction conditions (see the Supporting Information). This experiment constitutes further evidence that the two enantiomers of the M-B-H adduct show different reactivities under asymmetric $\mathrm{Rh} / \mathrm{bi}$ phosphine catalysis. 
In a final set of optimization experiments, the relative amount of the M-B-H adduct $\mathbf{2 a}$ was modified. Using either 3 or 4 equivalents of $\mathbf{2 a}$, the yield of $\mathbf{3 a}$ was not improved $\left(41 \%\right.$ and $42 \%$, respectively). ${ }^{[10]}$ Therefore, we decided to use only 1.5 equivalents of the M-B-H adduct. In order to study the effect of the hydroxy group of the M-B-H adduct in the cycloaddition process, acetyl- and Boc-protected M-B-H adducts were tested using the optimized reaction conditions. In neither case was cycloadduct 3a obtained, indicating that the free hydroxy group has a determining role in the process.

Having established the background for the kinetic resolution that operates in the described process, we again focused on the stereoselective synthesis of highly functionalized cyclohexadienes, proceeding to evaluate the scope of the reaction by varying both the tethers of the diyne and the M-B-H adduct.

Diyne 1b containing a 4-nitrobenzenesulfonamide (NNs) instead of $N$-tosylsulfonamide was used since this group could be deprotected under milder reaction conditions $^{[11]}$ (compounds 3b-3d, Scheme 3 ). Substituents in the para-position of the phenyl ring of $\mathbf{2}$ with different electronic demand $(\mathrm{OMe}, \mathrm{Cl})$ gave the corresponding cycloadducts with good yields and high enantiomeric excesses. In the case of cycloadduct $\mathbf{3 b}$, we tested again the effect of increasing the M-B-H adduct equivalents. With 2,3 or 4 equiv. of 2a, the
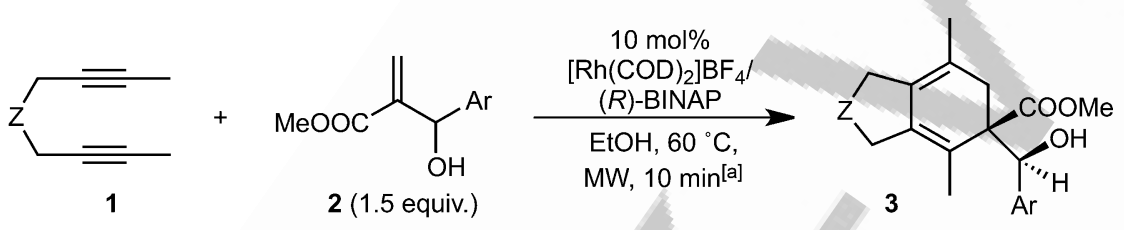<smiles>COC(=O)[C@]1([C@@H](O)c2ccc([18OH])cc2)CC(C)=C2CN([As])CC2=C1C</smiles>

$51 \%$ yield, $94 \%$ ee<smiles>COC(=O)[C@](O)(c1ccc(Cl)cc1)[C@@H](O)c1ccccc1</smiles>

$(+)-3 d$

$40 \%$ yield, $92 \%$ ee

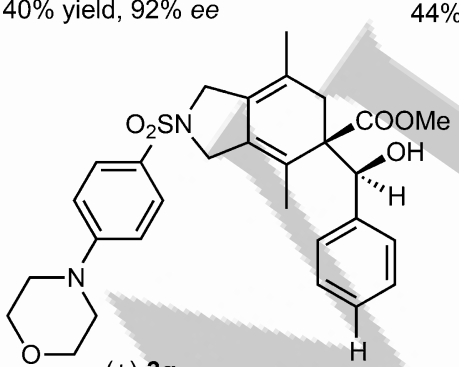

$(+)-3 \mathbf{g}$

$49 \%$ yield, $94 \%$ ee

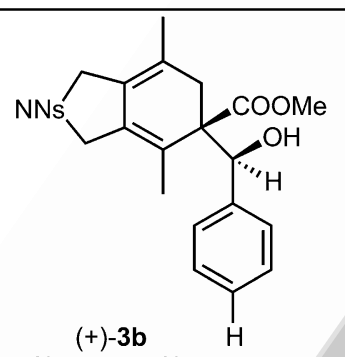
$38 \%$ yield, $92 \%$ ee<smiles>CO[C@H](c1ccc(C)cc1)[C@@]1(O)CC(C)=C2C[N+](=O)CC2=C1C</smiles>
$27 \%$ yield, $84 \%$ ee<smiles></smiles>

$(-)-3 d^{[c]}$

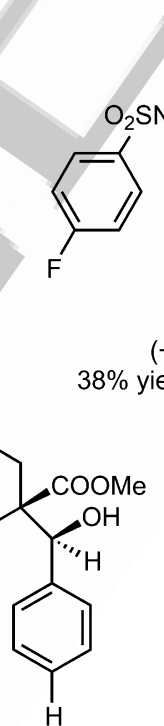

$(+)-3 h$

$30 \%$ yield, $97 \%$ ee

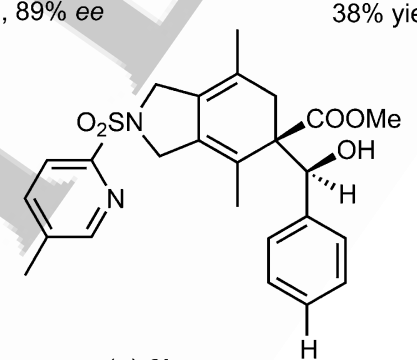

$+-3 e$<smiles>COc1ccc([C@@H](O)[C@]2(O)CC(C)=C3C[S@@](=O)([O-])CC3=C2C)cc1</smiles><smiles>COc1ccc([C@H](O)C2(C(=O)O)CC(C)=C3C[N+](=O)CC3=C2C)cc1</smiles>
$42 \%$ yield, $95 \%$ ee $49 \%$ yield, $89 \%$ ee<smiles></smiles>
$48 \%$ yield, $95 \%$ ee<smiles>CCOC(=O)C1(C(=O)OCC)CC2=C(C)CC(C(=O)OC)([C@H](O)c3ccc(I)cc3)C(C)=C2C1</smiles>

$3 \mathbf{i}$ $<5 \%$ yield $^{[c]}$<smiles>COC(=O)[C@]1([C@@H](O)c2ccccc2)CC(C)=C2COCC2=C1C</smiles>
$\%$ yield $[$ [c]

[a] Conditions: $1 \mathrm{a}$ (10 mmols, 1 equiv.), 2 (1.5 equiv.). The cited yields were of isolated products. Enantiomeric excesses were determined by chiral HPLC.

[b] (S)-BINAP was used.

[c] The reaction was carried out at $80^{\circ} \mathrm{C}(\mathrm{MW})$ for $10 \mathrm{~min}$. Yield estimated by NMR.

Scheme 3. Scope of the process. 
yield was only improved to $43 \%, 45 \%$ and $56 \%$, respectively. Using the enantiomeric $(S)$-BINAP ligand, $(-)-\mathbf{3 b},(-)-\mathbf{3 c}$ and $(-)-\mathbf{3 d}$ (Scheme 3 ) were obtained in high ees. We then changed the substituent in the para position of the phenyl ring at the sulfonamide tether. Fluoride and bromide substituted diynes led to $(+)-3 \mathbf{e}$ and $(+)-3 \mathbf{f}$ with high enantiomeric excesses (Scheme 3). Changing the para substituent to a bulkier moiety such as a morpholine ring did not affect the yield or the enantiomeric excess, affording compound $(+)-3 g$ in a $49 \%$ yield with $94 \%$ ee A diyne bearing the 5-methyl-2-pyridinesulfonyl group provided (+)-3h in a $30 \%$ yield with $97 \%$ ee The presence of a nitrogen atom in the molecule did not seem to affect the process by poisoning the catalyst. However, M-B-H adduct $\mathbf{2 a}$ failed to provide significant amounts of cycloadducts $\mathbf{3 i}$ and $\mathbf{3 j}$ when reacted with malonate and oxygen tethered diynes.

$\mathrm{M}-\mathrm{B}-\mathrm{H}$ adducts containing heteroaromatic rings such as thiophene, furan, benzothiophene, and benzofuran were then synthesized and tested as more challenging substrates (Scheme 4). In all cases, the corre-
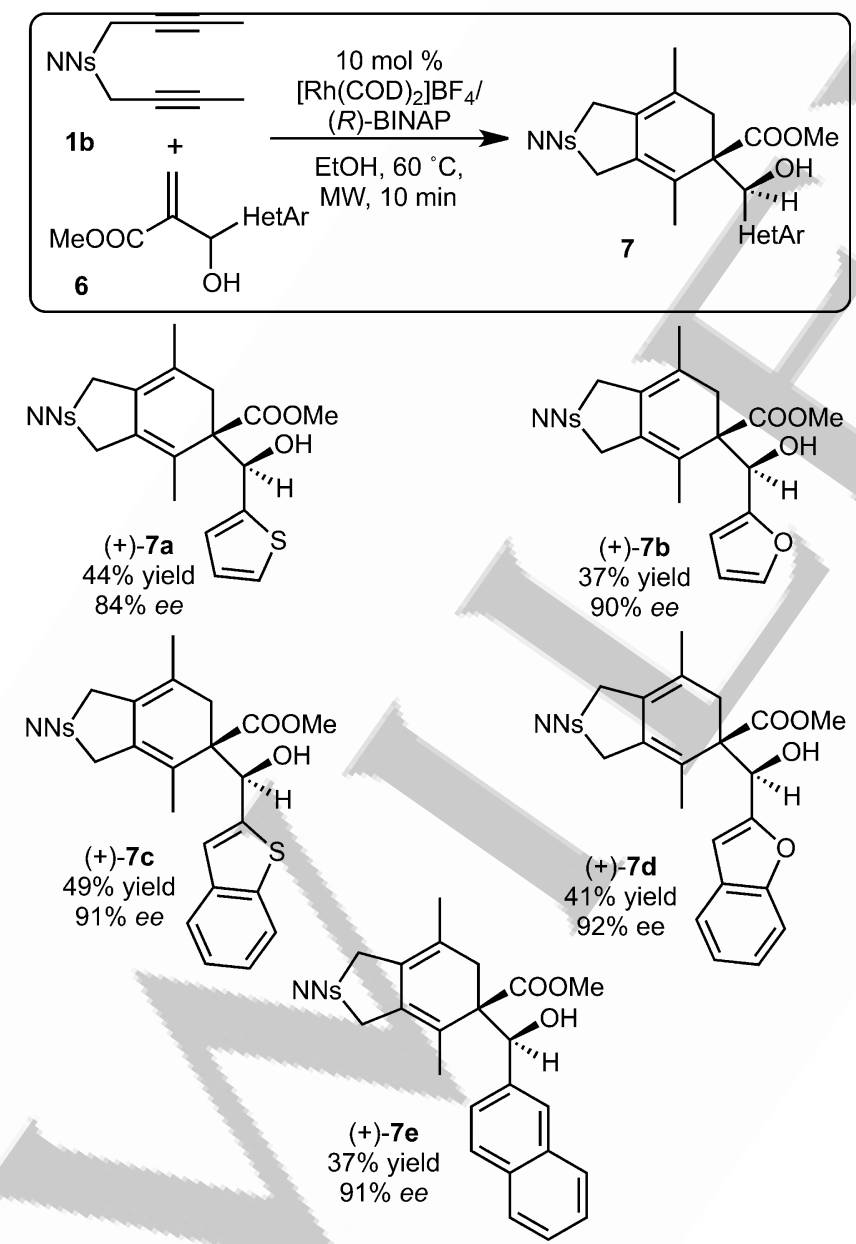

Scheme 4. $[2+2+2]$ cycloaddition reactions between diyne 1b and Morita-Baylis-Hillman adducts 6.

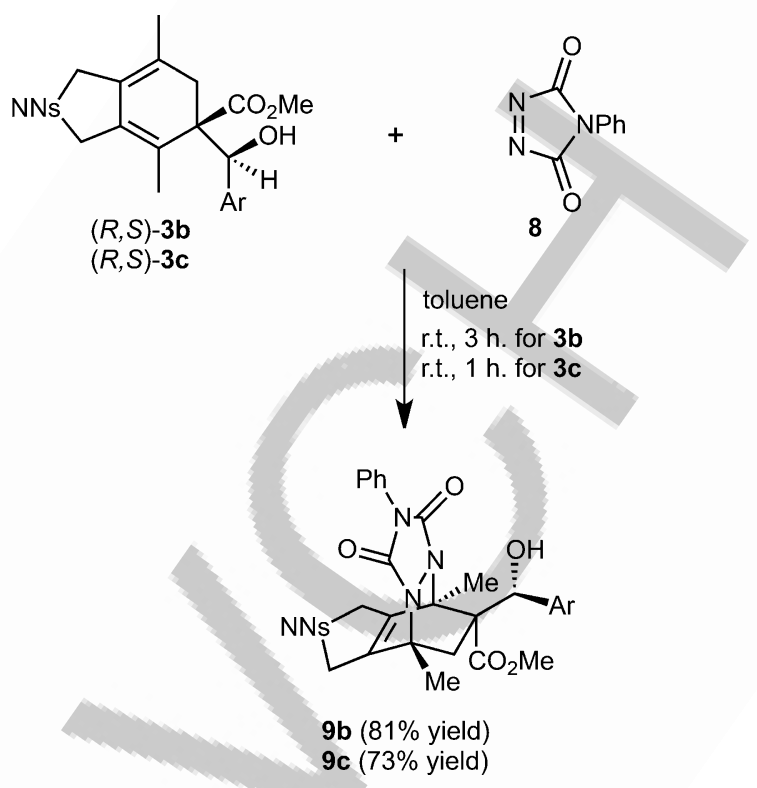

Scheme 5. Diels-Alder cycloaddition between 1,3-cyclohexadienes $\mathbf{3 b}$ and $\mathbf{3 c}$ and dienophile $\mathbf{8}$.

sponding cycloadducts were obtained with high enantioselectivities. Thus, a heteroatom in the M-B-H adduct did not affect the process and did not poison the rhodium catalyst. Finally, an effective reaction was also obtained with an M-B-H adduct with a naphthalene group (Scheme 4). The relative and absolute configurations of $\mathbf{3 b}-\mathbf{3 h}$ and $\mathbf{7 a}-\mathbf{7 e}$ were tentatively assigned by analogy with (+)-3a.

We then exploited the 1,3-cyclohexadiene derivatives generated by the $[2+2+2]$ cycloaddition reaction to access more densely functionalized scaffolds via Diels-Alder reactions ${ }^{[2]}$ (Scheme 5). A reactive nitrogen-containing heterodienophile, $N$-phenyltriazolinedione $\mathbf{8}$, was reacted with the unactivated and highly substituted cycloadducts $\mathbf{3 b}$ and $\mathbf{3 c}$ in toluene at room temperature, leading to $\mathbf{9 b}$ and $\mathbf{9 c}$, respectively, in high yields. 2D NMR experiments (see the Supporting Information) of the Diels-Alder adducts revealed a highly diastereoselective [4+2] cycloaddition occurring to the opposite side of the ester group. In both cases, traces of the stereoisomer resulting from addition of $\mathbf{8}$ to the same face of the ester group were also observed (see the Supporting Information).

To summarize, we have developed a diastereo- and enantioselective $[2+2+2]$ cycloaddition reaction between diynes and Morita-Baylis-Hillman adducts using a combination of $\left[\mathrm{Rh}(\mathrm{COD})_{2}\right] \mathrm{BF}_{4}$ and chiral BINAP ligands. A kinetic resolution of the M-B-H adduct was achieved generating an optically pure 1,3cyclohexadiene containing vicinal tertiary and quaternary carbon centres. Furthermore, Diels-Alder reactions using these dienes as substrates occurred in a highly diastereoselective fashion to provide densely functionalized polycyclic scaffolds. 


\section{Experimental Section}

\section{General Procedure for the Rh-Catalyzed [2+2+2] Cycloaddition Reactions}

A stirred mixture of $\left[\mathrm{Rh}(\mathrm{COD})_{2}\right] \mathrm{BF}_{4}(4.1 \mathrm{mg}, 0.01 \mathrm{mmol}$, 0.1 equiv.) and $(R)$-BINAP ( $6.3 \mathrm{mg}, 0.01 \mathrm{mmol}, 0.1$ equiv.) in dichloromethane $(2 \mathrm{~mL})$ was degassed under nitrogen. Hydrogen gas was introduced to the catalyst solution and the mixture was stirred for $30 \mathrm{~min}$. The resulting mixture was concentrated to dryness. Ethanol $(3 \mathrm{~mL})$ was then added and the solution was stirred under a nitrogen atmosphere. The solution was introduced to a $10-\mathrm{mL}$ screw-capped vial. To this solution Morita-Baylis-Hillman adduct $\mathbf{2}$ or $\mathbf{6}$ ( $0.15 \mathrm{mmol}, 1.5$ equiv.) and diyne $\mathbf{1}$ ( $0.1 \mathrm{mmol}, 1$ equiv.) were added under a nitrogen atmosphere. The vial was then placed inside the cavity of the microwave synthesizer. The reaction mixture was heated at $60^{\circ} \mathrm{C}$ for $10 \mathrm{~min}$ (TLC monitoring). The solvent was then evaporated and the residue was purified by column chromatography on silica gel to give compounds 3 or 7.

\section{Acknowledgements}

Financial support from the Spanish Ministry of Education and Science (MINECO) (Projects No.: CTQ2014-54306-P, CTQ2012-32436 and a RyC contract to A. L.) and the DIUE of the Generalitat de Catalunya (Project No.: 2014SGR931) are acknowledged. Thanks are due to Generalitat de Catalunya for predoctoral grants to M.F. and M.P.

\section{References}

[1] For selected reviews, see: a) E. J. Corey, A. GuzmanPerez, Angew. Chem. 1998, 110, 2092; Angew. Chem. Int. Ed. 1998, 37, 388; b) I. Denissova, L. Barriault, Tetrahedron 2003, 59, 10105; c) C. J. Douglas, L. E. Overman, Proc. Natl. Acad. Sci. USA 2004, 101, 5363; d) B. M. Trost, C. Jiang, Synthesis 2006, 369; e) M. Bella, T. Gasperi, Synthesis 2009, 1583; f) B. Wang, Y. Q. Tu, Acc. Chem. Res. 2011, 44, 1207; g) Y. Liu, S. J. Han, W.-B. Liu, B. M. Stoltz, Acc. Chem. Res. 2015, 48, 740.

[2] For selected and recent reviews, see: a) A. Thakur, J. Louie, Acc. Chem. Res. 2015, 48, 2354; b) M. Amatore, C, Aubert, Eur. J. Org. Chem. 2015, 265; c) Y. Satoh, Y. Obora, Eur. J. Org. Chem. 2015, 5041; d) D. L. J. Broere, E. Ruijter, Synthesis 2012, 2639; e) S. Okamoto, Heterocycles 2012, 85, 1579; f) Y. Shibata, K. Tanaka, Synthesis 2012, 323; g) N. Weding, M. Hapke, Chem. Soc. Rev. 2011, \#\#40\#\#15, 4525; h) R. Hua, M. V. A. Abrenica, P. Wang, Curr. Org. Chem. 2011, 15, 712 ; i) M. R. Shaaban, R. El-Sayed, A. H. M. Elwahy, Tetrahedron 2011, 67, 6095; j) G. Domínguez, J. PérezCastells, Chem. Soc. Rev. 2011, 40, 3430; k) A. PlaQuintana, A. Roglans, Molecules 2010, 15, 9230. 1) For a monography, see: Transition-metal-mediated aromatic ring construction, (Ed.: K. Tanaka), Wiley, Hoboken, 2013.

[3] For selected references, see: a) T. Shibata, Y. Arai, Y. Tahara, Org. Lett. 2005, 7, 4955; b) S. Brun, L. Garcia, I. González, A. Torrent, A. Dachs, A. Pla-Quintana, T. Parella, A. Roglans, Chem. Commun. 2008, 4339; c) A. Geny, S. Gaudrel, F. Slowniski, M. Amatore, G. Chouraqui, M. Malacria, C. Aubert, V. Gandon, Adv. Synth. Catal. 2009, 351, 271; d) A. Dachs, A. Pla-Quintana, T. Parella, M. Solà, A. Roglans, Chem. Eur. J. 2011, 17, 14493; e) T. León, M. Parera, A. Roglans, A. Riera, X. Verdaguer, Angew. Chem. 2012, 124, 7057; Angew. Chem. Int. Ed. 2012, 51, 6951; f) K. Masutomi, N. Sakiyama, K. Noguchi, K. Tanaka, Angew. Chem. 2012, 124, 13208; Angew. Chem. Int. Ed. 2012, 51, 13031.

[4] For selected references, see: a) K. Tsuchikama, Y. Kuwata, T. Shibata, J. Am. Chem. Soc. 2006, 128, 13686; b) T. Shibata, A. Kawachi, M. Ogawa, Y. Kuwata, K. Tsuchikama, K. Endo, Tetrahedron 2007, 63, 12853; c) K. Tanaka, M. Takahashi, H. Imase, T. Osaka, K. Noguchi, M. Hirano, Tetrahedron 2008, 64, 6289; d) M. Kobayashi, T. Suda, K. Noguchi, K. Tanaka, Angew. Chem. 2011, 123, 1702; Angew. Chem. Int. Ed. 2011, 50, 1664.

[5] For selected reviews, see: a) D. Basavaiah, P. D. Rao, R. S. Hyma, Tetrahedron 1996, 52, 8001; b) D. Basavaiah, A. J. Rao, T. Satyanarayana, Chem. Rev. 2003, 103, 811; c) V. Singh, S. Batra, Tetrahedron 2008, 64, 4511; d) D. Basavaiah, B. S. Reddy, S. S. Badsara, Chem. Rev. 2010, 110, 5447; e) T.-Y. Liu, M. Xie, Y.-C. Chen, Chem. Soc. Rev. 2012, 41, 4101; f) D. Basavaiah, G. Veeraraghavaiah, Chem. Soc. Rev. 2012, 41, 68.

[6] For selected references on the stereocontrolled reaction of M-B-H adducts, see: a) T. Gendrineau, N. Demoulin, L. Navarre, J.-P. Genet, S. Darses, Chem. Eur. J. 2009, 15, 4710; b) Y. Wang, X. Feng, H. Du, Org. Lett. 2011, 13, 4954. For a reference to the kinetic resolution of tertiary propargylic alcohols by a $[2+2+2]$ cycloaddition, see: c) K. Tanaka, T. Osaka, K. Noguchi, M. Hirano, Org. Lett. 2007, 9, 1307.

[7] CCDC 1429936 (compound 3a) contains the supplementary crystallographic data for this paper. These data can be obtained free of charge from The Cambridge Crystallographic Data Centre via www.ccdc.cam.ac.uk/data_request/cif.

[8] The low ee obtained can be justified on the grounds of a competing enantiocomplementary isomerization process of the M-B-H adduct. When the isomerization process is suppressed a higher ee is obtained (vide infra).

[9] K. Ren, L. Zhang, B. Hu, M. Zhao, Y. Tu, X. Xie, T. Y. Zhang, Z. Zhang, ChemCatChem 2013, 5, 1317.

[10] The reaction shows substrate inhibition when a high excess of M-B-H adduct is used. Our interpretation is that this inhibition is probably due to coordination of multiple M-B-H adducts to the rhodium complex.

[11] T. Fukuyama, C.-K. Jow, M. Cheung, Tetrahedron Lett. 1995, 36, 6373.

[12] a) A. L. Jones, J. K. Snyder, Org. Lett. 2010, 12, 1592; b) M. Shibuya, T. Sudoh, T. Kawamura, Y. Yamamoto, Org. Biomol. Chem. 2015, 13, 5862. 


\section{UPDATES}

Rhodium-Catalyzed [2+2+2] Cycloadditions of Diynes with Morita-Baylis-Hillman Adducts: A Stereoselective Entry to Densely Functionalized Cyclohexadiene Scaffolds

Adv. Synth. Catal. 2016, 358, $1-7$

$\square$ Martí Fernández, Magda Parera, Teodor Parella,
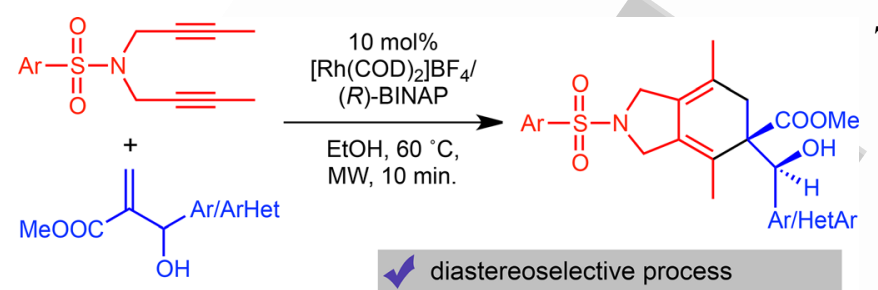

Agustí Lledó, Jean Le Bras, Jacques Muzart,

Anna Pla-Quintana,* Anna Roglans*

diastereoselective process kinetic resolution of the MoritaBaylis-Hillman adduct products with a tertiary/quaternary stereodiad in $84-97 \%$ ee

Anna Pla-Quintana, Anna Roglans"

